\title{
Vasculite Cutânea Induzida por Propiltiouracil
}

\section{Propy/thiouracil-Induced Cutaneous Vasculitis}

\author{
Fernanda Manente Milanez ${ }^{(1)}$, Leonardo Atem Gonçalves A. Costa ${ }^{(1)}$, Fábio Freire José(2), \\ Milvia M. S. S. Enokihara ${ }^{(3)}$, Alexandre Wagner Silva de Souza ${ }^{(4)}$
}

\section{RESUMO}

O uso do propiltiouracil (PTU) está associado ao desenvolvimento de diferentes auto-anticorpos, entre eles anticorpos anticitoplasma de neutrófilos (ANCA), que estão envolvidos na patogênese das vasculites sistêmicas ANCA-associadas (VSAA). Será relatado o caso de um paciente do sexo feminino, de 46 anos, que apresentou vasculite cutânea durante o uso de PTU como terapêutica para doença de Graves. O ANCA com padrão perinuclear ( $\mathrm{p}$-ANCA) foi positivo em títulos $\geq 1 / 320$, porém anticorpos antimieloperoxidase (MPO) não foram detectados. A biópsia de pele revelou uma vasculite leucocitoclástica. Houve melhora clínica em dez dias após a retirada do PTU e optou-se pelo iodo radioativo $\left(\mathrm{I}^{131}\right)$ para o tratamento do hipertireoidismo. O p-ANCA mantevese positivo em títulos $\geq 1 / 320$ em duas medidas, realizadas oito meses e quatro anos após a suspensão do PTU.

Palavras-chave: anticorpos anticitoplasma de neutrófilos, vasculite, propiltiouracil, hipertireoidismo.

\section{INTRODUÇÃO}

O hipertireoidismo é uma doença endócrina auto-imune bastante prevalente, e as medicações de escolha para o tratamento são, com muita freqüência, o propiltiouracil (PTU) e o metimazol. O tratamento com PTU geralmente tem duração prolongada e diversos efeitos colaterais são descritos, entre os quais agranulocitose, anemia aplástica e pneumonia intersticial ${ }^{(1,2)}$.

O uso do PTU tem sido relacionado ainda à formação de auto-anticorpos, como anticorpos anticitoplasma de neutrófilos (ANCA), e às manifestações de doenças autoimunes, que incluem vasculite cutânea e lúpus induzido por drogas (LID). A vasculite induzida por PTU geralmente

\begin{abstract}
The use of propylthiouracil (PTU) is associated with the development of different auto-antibodies, amongst them are antineutrophil cytoplasmic antibodies (ANCA) that are involved in the pathogenesis of ANCA associated systemic vasculitis. The case of a 46-years old woman who presented cutaneous vasculitis when taking PTU for Graves' disease is reported. Perinuclear ANCA ( $p$-ANCA) was positive with titer $\geq 1 / 320$, but anti-myeloperoxidase antibodies were not detected. Skin biopsy showed leucocytoclastic vasculitis. The patient improved within ten days after withdrawing PTU and the resolution of hyperthyroidism was achieved with radioiodine $\left({ }^{131} I\right)$. The $p$-ANCA test remained positive $\geq 1 / 320$ eight months and four years after PTU withdrawal.
\end{abstract}

Keywords: antineutrophil cytoplasmic antibodies, vasculitis, propylthiouracil, hyperthyroidism.

cursa com a presença de p-ANCA e com manifestações musculoesqueléticas e vasculite cutânea, que freqüentemente regridem após a suspensão do medicamento ${ }^{(1-3)}$.

Outras medicações como hidralazina, penicilamina, procainamida e alopurinol também podem estar relacionadas a quadros de vasculites ANCA-associadas, porém com freqüência bem menor da relatada com o uso das medicações antitireoidianas, em especial o $\mathrm{PTU}^{(1)}$.

A associação entre a positividade dos ANCAs e as vasculites é conhecida, porém sua fisiopatologia ainda não é totalmente compreendida ${ }^{(3)}$. Neste artigo, será descrito o caso de uma paciente que apresentou manifestações de vasculite cutânea com a presença de ANCA relacionada ao uso de PTU.

Recebido em 20/8/2007. Aprovado, após revisão, em 13/9/2008. Declaramos a inexistência de conflitos de interesse

1. Residente de clínica médica do Hospital do Servidor Público Estadual Francisco Morato de Oliveira (HSPE-FMO)

2. Médico-assistente da disciplina de Clínica Médica da Escola Paulista de Medicina da Universidade Federal de São Paulo (Unifesp/EPM)

3. Assistente doutora da disciplina de Patologia da Unifesp/EPM.

4. Assistente doutor da disciplina de Reumatologia da Unifesp/EPM.

Endereço para correspondência: Alexandre W. S. Souza, Rua Botucatu, 740, disciplina de reumatologia, CEP 04023-900, São Paulo, SP, e-mail: alexandre_wagner@uol.com.br 


\section{RELATO DE CASO}

Paciente feminina, 46 anos, passou a apresentar lesões inicialmente em coxa direita que evoluíram, em três dias, para abdômen e membros. Ao mesmo tempo, relatou dor intensa no lobo da orelha direita seguida do surgimento de placa eritêmato-violácea com necrose central. A paciente referia lesões cutâneas similares recorrentes, além de artralgias de grandes articulações nos últimos seis meses. As lesões melhoravam espontaneamente em média três dias após o início. Ela recebera o diagnóstico de doença de Graves há três anos e estava em uso de PTU, $300 \mathrm{mg}$ por dia desde então. A paciente utilizava ainda enalapril para hipertensão e ciclobenzaprina para fibromialgia. Negava histórico de atopia. Ao exame físico, apresentava múltiplas placas eritêmato-violáceas nos membros inferiores (Figura l) e no lobo da orelha direita. Algumas dessas placas apresentavam centro necrótico. Não foram observados bócio, artrite ou outras anormalidades ao exame físico.

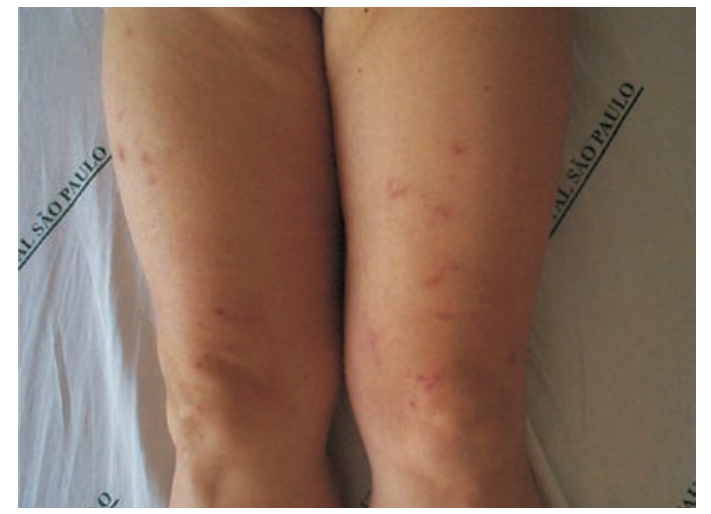

Figura 1 - Placas eritêmato-violáceas em membros inferiores. Algumas delas apresentam centro necrótico.

O hemograma, a urina tipo I e a creatinina foram normais à admissão, a velocidade de hemossedimentação (VHS) foi de $35 \mathrm{~mm}$ na primeira hora, proteína $\mathrm{C}$ reativa (PCR) de $2,1 \mathrm{mg} / \mathrm{dL}$ (referência $<0,8 \mathrm{mg} / \mathrm{dL}$ ) e a dosagem de hormônios tireoidianos (TSH e tiroxina livre) foi normal. Anticorpos antitireoglobulina e antitireoperoxidase foram positivos. Fator antinuclear (FAN) e sorologias para hepatite $\mathrm{B}$ e $\mathrm{C}$ foram negativos. A pesquisa de ANCA foi positiva, com padrão perinuclear e um título $\geq 1 / 320$, mas não foram detectados anticorpos anti-MPO, pelo método ELISA (enzyme-linked immunosorbent assay). Biópsia de pele em uma lesão ativa demonstrou vasculite leucocitoclástica (Figura 2).

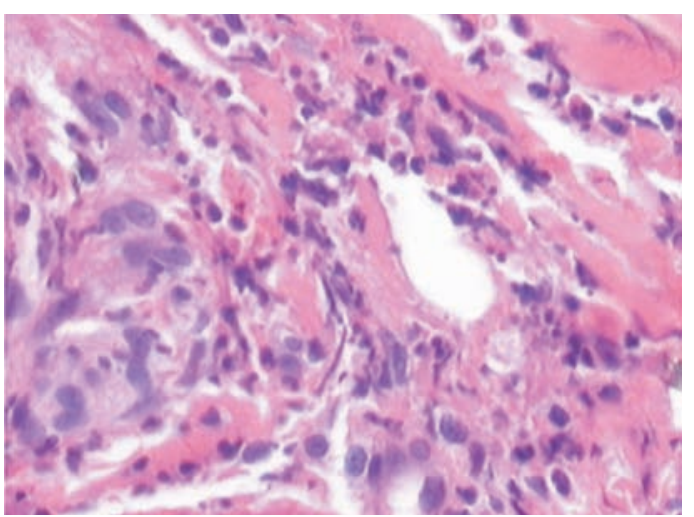

Figura 2 - Vasculite leucocitoclástica em biópsia de pele (hematoxilina-eosina, aumento $\times 400)$.

O PTU foi suspenso, e a paciente apresentou melhora das lesões cutâneas e das dores articulares em dez dias. $\mathrm{Na}$ evolução, a paciente apresentou sinais de hipertireoidismo e diminuição dos níveis de TSH. Três meses após a retirada da medicação, foi submetida ao tratamento com iodo radioativo $\mathrm{I}^{131}$ e evoluiu com hipotireoidismo, necessitando utilizar levotiroxina. Foram realizadas duas novas pesquisas de ANCA: uma após oito meses e outra após quatro anos da retirada do PTU. Ambas foram positivas com padrão perinuclear em títulos $\geq 1 / 320$. A paciente não apresentou novas manifestações de vasculite durante o seguimento de quatro anos.

\section{DISCUSSÃO}

A paciente relatada apresentou uma vasculite cutânea, artralgias e p-ANCA positivo (1/320) após uso prolongado de PTU. A relação causal entre as manifestações clínicas e o uso do PTU é sugerida pela melhora do quadro logo após a retirada da droga ${ }^{(1-3)}$. Além disso, o acometimento do lobo da orelha é freqüentemente descrito em séries de casos de vasculites relacionadas ao PTU, e essa característica pode ajudar na suspeita dessa associação ${ }^{(4-6)}$.

O ANCA é um importante marcador sorológico de vasculites sistêmicas como a granulomatose de Wegener, síndrome de Churg-Strauss e poliangiíte microscópica ${ }^{(7)}$. Os padrões perinuclear ( $\mathrm{p}$-ANCA) e citoplasmático (c-ANCA) são observados por meio de imunofluorescência indireta. MPO e proteinase-3 (PR3) são os principais antígenos para p-ANCA e c-ANCA, respectivamente, e sua detecção é usualmente feita por intermédio do $\operatorname{ELISA}^{(2,8)}$. Outros antígenos como catepsina-G, lactoferrina e elastase humana leucocitária são também associados ao p-ANCA ${ }^{(2,9,10)}$.

Propiltiouracil é uma medicação antitireoidiana comumente prescrita que tem sido associada à indução de ANCA 
e à vasculite ANCA-associada após uso prolongado ${ }^{(10-12)}$. A prevalência de ANCA em pacientes que tomam PTU varia de $4 \%$ a $46 \%$. Por sua vez, a incidência de vasculite é bem menor, chegando até $1,4 \%^{(3,10,11)}$. Anticorpos anti-MPO têm sido classicamente associados às manifestações de vasculites induzidas pelo PTU ${ }^{(3,11,13)}$. Contudo, alguns estudos demonstraram a presença de múltiplos antígenos associados aos ANCAs, além da mieloperoxidase ${ }^{(9,11)}$. A presença de anticorpos contra múltiplos antígenos foi encontrada em 92,6\% dos pacientes com manifestações de vasculite em comparação com apenas $31,6 \%$ nos pacientes sem vasculite ${ }^{(1,9,12)}$. Embora o anti-MPO tenha sido detectado em $67 \%$ a $92,6 \%$ dos pacientes com vasculite induzida por PTU, antilactoferrina e antielastase humana leucocitária foram também detectados em $81,5 \%$ e $55,6 \%$ dos casos, respectivamente ${ }^{(1,9)}$. A ausência de anticorpos anti-MPO nesse caso indica que outros antígenos além da mieloperoxidase podem estar envolvidos na patogênese das manifestações apresentadas pela paciente. Infelizmente, a identificação desses antígenos não está disponível de forma rotineira, sendo utilizada normalmente apenas para fins científicos.

Neste caso relatado, o p-ANCA persistiu positivo e em altos títulos, mesmo quatro anos após a suspensão do PTU e apesar de a paciente ter se mantido assintomática. Não há no momento estudos longitudinais que tenham avaliado se essa persistência aumenta o risco de recaída do quadro de vasculite. Em algumas séries e relatos de casos, a maioria dos pacientes manteve-se assintomática, apesar de o p-ANCA ter-se mantido positivo por meses ou anos após a retirada do $\mathrm{PTU}^{(2,12-14)}$.

\section{REFERÊNCIAS}

1. Aloush V, Litinsky I, Caspi D, et al.: Propylthiouracil-induced autoimmune syndromes: two distinct clinical presentations with different course and management. Semin Arthritis Rheum 36: 4-9, 2006.

2. Zhao MH, Chen M, Gao Y, et al.: Propylthiouracil-induced antineutrophil cytoplasmic antibody-associated vasculitis. Kidney Int 69: 1477-81, 2006.

3. Noh JY, Asari T, Hamada N, et al.: Frequency of appearance of myeloperoxidase-antineutrophil cytoplasmic antibody (MPOANCA) in Graves' disease patients treated with propylthiouracil and the relationship between MPO-ANCA and clinical manifestations. Clin Endocrinol (Oxf) 54: 651-4, 2001.

4. Sheen YS, Chu CY, Yu HS: Antineutrophil cytoplasmic antibodypositive cutaneous leukocytoclastic vasculitis associated with propylthiouracil therapy. Arch Dermatol 142: 879-80, 2006.

5. Carrasco MD, Riera C, Clotet B, et al.: Cutaneous vasculitis associated with propylthiouracil therapy. Arch Intern Med 147: 1677, 1987.
A doença de Graves é uma enfermidade relacionada à produção de auto-anticorpos, e a superposição de fenômenos auto-imunes em um mesmo paciente é fato há muito conhecido. Muitos autores questionam se a ocorrência de quadros auto-imunes induzidos pelo PTU nesses pacientes seria mais freqüente em virtude desse fato. Não está bem esclarecido se isso poderia explicar a indução de ANCA em usuários de PTU ${ }^{(1,12)}$. É sugerido que o acúmulo de metabólitos do PTU em neutrófilos possa tornar a mieloperoxidase imunogênica, como também outras enzimas presentes nos grânulos dos neutrófilos. A partir daí, ocorreria a ativação de outros neutrófilos, provocando a liberação de enzimas e produção de radicais livres e citocinas, resultando em dano vascular ${ }^{(1,15)}$.

A retirada da medicação é a principal medida recomendada para os pacientes que desenvolvem vasculite cutânea com ANCA positivo, induzida pelo PTU, pois freqüentemente leva à resolução completa do quadro ${ }^{(1,2,4)}$. O uso de corticóides e imunossupressores só é necessário em casos graves, quando há envolvimento de órgãos nobres, como os acometimentos renal ou pulmonar ${ }^{(2,8)}$.

Em conclusão, o caso aqui descrito é útil para alertar clínicos e reumatologistas sobre esse evento adverso que pode ocorrer a partir do uso prolongado do PTU. O reconhecimento imediato das manifestações e a retirada da droga são essenciais para a boa evolução dessa enfermidade.

\section{AGRADECIMENTOS}

Os autores agradecem à Silene Keusseyan por sua ajuda na realização de exames laboratoriais.

6. Vasily DB, Tyler WB: Propylthiouracil-induced cutaneous vasculitis. Case presentation and review of the literature. Jama 243: 458-61, 1980

7. Jennette JC, Falk RJ, Andrassy K, et al.: Nomenclature of systemic vasculitides. Proposal of an international consensus conference. Arthritis Rheum 37: 187-92, 1994.

8. Helfgott SM, Smith RN: Case records of the Massachusetts General Hospital. Weekly clinicopathological exercises. Case 21-2002. A 21-year-old man with arthritis during treatment for hyperthyroidism. N Engl J Med 347: 122-30, 2002.

9. Gao Y, Chen M, Ye H, et al.: The target antigens of antineutrophil cytoplasmic antibodies (ANCA) induced by propylthiouracil. Int Immunopharmacol 7: 55-60, 2007.

10. Gao $\mathrm{Y}$, Zhao MH, Guo XH, et al.: The prevalence and target antigens of antithyroid drugs induced antineutrophil cytoplasmic antibodies (ANCA) in Chinese patients with hyperthyroidism. Endocr Res 30: 205-13, 2004.

11. Slot MC, Links TP, Stegeman CA, et al.: Occurrence of antineutrophil cytoplasmic antibodies and associated vasculitis in 
patients with hyperthyroidism treated with antithyroid drugs: A long-term followup study. Arthritis Rheum 53: 108-13, 2005.

12. Bonaci-Nikolic B, Nikolic MM, Andrejevic S, et al.: Antineutrophil cytoplasmic antibody (ANCA)-associated autoimmune diseases induced by antithyroid drugs: comparison with idiopathic ANCA vasculitides. Arthritis Res Ther 7: R1072-81, 2005.

13. Nakamori $Y$, Tominaga $T$, Inoue $Y$, et al.: Propylthiouracil (PTU)-induced vasculitis associated with antineutrophil antibody against myeloperoxidase (MPO-ANCA). Intern Med 42: 529-33, 2003.

14. Harper L, Cockwell P, Savage CO: Case of propylthiouracilinduced ANCA associated small vessel vasculitis. Nephrol Dial Transplant 13: 455-8, 1998.

15. Xiao H, Heeringa P, Hu P, et al.: Antineutrophil cytoplasmic autoantibodies specific for myeloperoxidase cause glomerulonephritis and vasculitis in mice. J Clin Invest 110: 955-63, 2002. 